\title{
Dentistry to seek fresh assurances from new Secretary of State
}

Concerns over recruitment, funding and support for dentistry are likely to be high on the list of issues presented to the new Health and Social Care Secretary Matt Hancock by dentistry's leaders.

Hancock was appointed as the new Secretary of State on 9 July 2018 following a shuffle of positions in the Cabinet that led to former Health Secretary Jeremy Hunt moving to become Secretary of State for Foreign and Commonwealth Affairs.

Hunt was the longest ever serving Health Secretary - from September 2012 until July 2018.

Hancock moved from his post as Secretary of State for Digital, Culture, Media and Sport - a post he had only held since January of this year and was previously Minister of State for Digital from July 2016 to January 2018.
The MP for West Suffolk, Hancock served from 2010 as a backbencher on the Public Accounts Committee and the Standards \& Privileges Committee.

He has served in a number of ministerial roles, including for skills and business, and as Paymaster General and oversaw the expansion of apprenticeships, and championed the digital transformation of government.

The British Dental Association (BDA) said it had recently sought clarity from Hunt over the place of primary care and prevention within the NHS70 birthday spending pledge and that it would be seeking the same assurances from Hancock.

BDA Chair Mick Armstrong said: 'Failure to offer a credible costed plan for oral health is piling pressure across the NHS, most clearly illustrated by tooth decay's status as the number one reason for child hospital admissions.

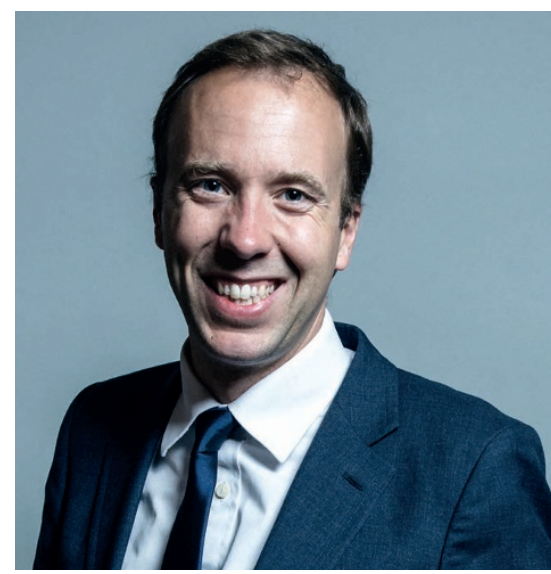

Health and Social Care Secretary Matt Hancock (Image courtesy of UK Parliament,

CC BY 3.0' https://creativecommons.org/licenses/by/3.0/)

'We had asked Mr Hunt to clarify if any of the recent spending boost would actually be put to work where it could achieve greatest effect and lasting change through prevention and public health.

'This profession has serious questions, and his successor will have to provide answers on whether dentistry will remain the missing piece in healthcare strategies.' 